\title{
Linguistic Influence on Russian and American Ethnobiological Categorization
}

\author{
Justin M. Nolan ${ }^{1}$, Aina Zaresheva ${ }^{2}$, and Michael C. Robbins ${ }^{3}$ \\ ${ }^{1}$ Department of Anthropology, University of Arkansas, Fayetteville, USA. ${ }^{2}$ Department of Russian and Slavonic Studies, \\ University of Missouri, Columbia, USA. ${ }^{3}$ Department of Anthropology, University of Missouri, Columbia, USA. \\ *ozarksanthro@msn.com
}

\begin{abstract}
In the Russian language, nouns are classified by gender and animacy, whereas in English, nouns are not. Using triad-sorts of names for biological and non-biological taxa, a comparison of results provided by native speakers of both languages reveals that cognitive categorizations of animate and inanimate nomenclatural forms differ significantly between speakers of Russian and American English. Speakers of American English appear to categorize names for living nouns more by phenotype than do Russians, who in turn appear to classify nouns more frequently on the basis of linguistic features such as gender. These results are believed to be pertinent to the elicitation and construction of folk ethnobiology taxonomies.

Received January 14, 2019

OPEN OACCESS

Accepted March 31, 2019

DOI 10.14237/ebl.10.1.2019.1497

Published May 30, 2019

Keywords Linguistic ethnobiology, Linguistic relativity, Folk taxonomies, Cognition and classification, Triad sorts

Copyright (C) 2019 by the author(s) licensee Society of Ethnobiology. This is an open-access article distributed under the terms of the Creative Commons Attribution-NonCommercial 4.0 International Public License (https://creativecommons.org/licenses/by-nc/4.0), which permits non-commercial use, distribution, and reproduction in any medium, provided the original author and source are credited.
\end{abstract}

\section{Introduction}

Linguistic ethnobiology represents an integral component of research in the study of human interactions and understanding of the natural world (Hunn and Brown 2011). Achieving cross-cultural understandings of folk classification systems embodied in human languages is crucial to the advancement of ethnobiology as a discipline (Berlin 1992; Brown 2001; Nolan and Robbins 2001). While a number of studies recognize the importance of various kinds of linguistic features when eliciting and constructing folk biological classifications (e.g., Baker 2003:109; Kilarski 2013; Zubin and Kopke 1986), relatively few empirical field studies actually demonstrate their semantic reality.

Here, we report the findings of a recent investigation of the cognitive categorization of plant and animal names in Russian and American English. Several compelling and consistent differences of ethnobiological interest were revealed. In particular, American English speakers appear to employ phenotypic (morphological/phylogenetic) criteria more frequently when categorizing both animate and inanimate folk biological taxa than do Russians speakers, who more often appear to use "linguistic" or "other" unknown criteria.

Scope of the Present Study

Comparing Russian and English language speakers from an ethnobiological perspective is especially fruitful for two main reasons: first, unlike English, Russian nouns are tri-classified by gender (masculine, feminine, and neuter), and further subdivided by "animacy" into an animate or inanimate, unmarked, dichotomous category. The animate category contains all members of the kingdom Animalia. Exceptions include the ambiguous status of microorganisms like protozoa (Beresford 1965:54). Most Americans, unfamiliar with the Russian language, express surprise upon learning that when inquiring about an animal (for example, a dog), one asks "Who is that?" rather than, as in English, "What is that?" Animacy also plays a significant grammatical role in Russian (e.g., serving as a masculine subgender in the accusative case). While many other languages make use of gender distinctions (e.g., French, German, etc.) or have noun classes (e.g., Swahili, Kikuyu, etc.), Russian has both. For more on the cognitive roots of gender 
in Russian see Kravchenko (2002), and for more on the role of animacy in Russian, see Klenin (1983).

The second reason the study is ethnobiologically significant is that without a "control group" it can be difficult to demonstrate specific influences on cognition and categorization. In order to gain conviction that specific cognitive decisions are in fact being influenced by certain linguistic features (and not others), it helps to be able to make systematic comparisons with languages not recognizing these same features. American English is such an example with regard to gender and animacy in Russian.

\section{Methods}

To avoid respondent tedium, a small sample of eight common words representing both human/nonhuman animate and living/non-living inanimate categories featuring both male and female Russian genders were selected. Neuter was excluded because of few, if any, animate examples. These terms are displayed in Table 1. The method of triad-sorts (Weller 1998) was deployed to measure cognitive similarities and differences in words. An array of all possible triads of words was first constructed and each respondent was then asked to: "select the one item most different from the other two" in each triad. This choice indicates that the unselected pair is the most similar.

Since the number of different triads is equivalent to determining $\mathrm{C}(\mathrm{n}, \mathrm{r})$ where $\mathrm{C}=\mathrm{n}$ !/ (r! (n-r)!), when the total number of $C$ combinations of $n$ items taken $r$ at a time, the number of different triads of the eight words in the matrix return 56 possible combinations. The 56 noun-triads and instructions were translated into Russian and administered to a sample of 56 Russians. Most live in the Saratov Region of southwestern Russia. The mean and median age were 20.1 and 19, respectively, and $86 \%$ were female. A comparable American sample of 53 respondents at
Table 1 Matrix of Russian gender and subgender classifications.

\begin{tabular}{lll}
\hline Gender & Animate & Inanimate \\
\hline Male & Father & House \\
& Bear & Flower \\
Female & Mother & Water \\
& Dog & Grass \\
\hline
\end{tabular}

the Universities of Arkansas and Missouri, 64\% of whom were female with mean and median ages of 24.5 and 21 , respectively, were also surveyed in the study.

Of special ethnobiological interest are the comparative responses of Russians and Americans to the animate pair (dog-bear) and the inanimate pair (flower-grass). The noun deemed "most different" in each triad reflects differentiations with respect to gender (e.g., masculine or feminine), phenotype (e.g., grass and flower, dog and bear), or other (e.g., random choice, symbolic). To illustrate accordingly, the following underlined terms indicate how items are deemed as most different from the other two on the basis of gender (dog-house-bear, flower-water-grass), phenotype (dog-house-bear, flower-water-grass), and other (dog-house-bear, flower-water-grass).

\section{Results and Discussion}

Using a difference of proportions statistical test, the results in Tables 2 and 3 below indicate that: (1) overall, Americans make significantly more similarity pairings by phenotype than Russians. They also show that this is true with respect to both the animate (dogbear) and the inanimate pairs (flower-grass). For example, Table 3 shows that $61 \%$ of the time Russians pair bear and dog when flower is the third item, while Americans paired bear-dog $89 \%$ of the time, indicating that Americans use a phenotype criterion significantly more ( $p$-value $<0.001)$; (2) Russians make significantly more similarity pairings by gender than

Table 2 Overall proportional category comparisons.

\begin{tabular}{lllllll}
\hline Category & RA & AA & RIA & AIA & RT & AT \\
\hline Phenotype & 0.60 & 0.82 & 0.69 & 0.91 & 0.64 & 0.87 \\
Gender & 0.60 & 0.08 & 0.17 & 0.04 & 0.19 & 0.06 \\
Other & 0.20 & 0.05 & 0.14 & 0.10 & 0.17 & 0.07 \\
\hline
\end{tabular}

$\mathrm{RA}=$ Russian Animate, $\mathrm{AA}=$ American Animate, $\mathrm{RIA}=$ Russian Inanimate, $\mathrm{AIA}=\mathrm{American}$ Inanimate, $\mathrm{RT}=$ Russian Total, AT=American Total.

*All categorical differences between Russian and American proportions are statistically significant $p$-value $<0.001$, except between other RIA and AIA ( $p$-value>0.05). 
Table 3 Comparisons of pairings by phenotype and gender.

\begin{tabular}{|c|c|c|c|c|c|}
\hline Category & Third Item & Russian (N) & \% Respondents & American (N) & \% Responses \\
\hline \multirow[t]{6}{*}{ Phenotype: Animate (dog-bear) } & mother & 33 & $59 \%$ & 40 & $75 \%$ \\
\hline & house & 27 & $48 \%$ & 43 & $81 \% * * *$ \\
\hline & flower & 34 & $61 \%$ & 47 & $89 \% * * *$ \\
\hline & water & 40 & $71 \%$ & 44 & $83 \%$ \\
\hline & father & 32 & $57 \%$ & 43 & $81 \% * *$ \\
\hline & grass & 35 & $63 \%$ & 45 & $85 \% * *$ \\
\hline \multirow[t]{6}{*}{ Phenotype: Inanimate (flower-grass) } & dog & 43 & $77 \%$ & 48 & $91 \% *$ \\
\hline & mother & 37 & $66 \%$ & 48 & $91 \% * *$ \\
\hline & house & 35 & $63 \%$ & 50 & $94 \% * * *$ \\
\hline & water & 35 & $63 \%$ & 46 & $89 \% * *$ \\
\hline & father & 43 & $77 \%$ & 48 & $91 \% *$ \\
\hline & bear & 39 & $70 \%$ & 50 & $94 \% * *$ \\
\hline \multirow[t]{6}{*}{ Gender: Animate (dog-bear) } & mother & 19 & $34 \%$ & 12 & $23 \%$ \\
\hline & house & 6 & $11 \%$ & 0 & $0 \%$ \\
\hline & flower & 10 & $18 \%$ & 1 & $2 \% * *$ \\
\hline & water & 11 & $20 \%$ & 8 & $15 \%$ \\
\hline & father & 10 & $18 \%$ & 1 & $2 \% * *$ \\
\hline & grass & 12 & $21 \%$ & 2 & $4 \% *$ \\
\hline \multirow[t]{6}{*}{ Gender: Inanimate (flower-grass) } & dog & 9 & $16 \%$ & 3 & $6 \%$ \\
\hline & mother & 9 & $16 \%$ & 0 & $0 \% * *$ \\
\hline & house & 12 & $21 \%$ & 1 & $2 \% * *$ \\
\hline & water & 12 & $21 \%$ & 4 & $8 \%$ \\
\hline & father & 8 & $14 \%$ & 2 & $4 \%$ \\
\hline & bear & 8 & $14 \%$ & 2 & $4 \%$ \\
\hline
\end{tabular}

Probable proportional difference: ${ }^{*} p$-value $<0.05,{ }^{*} p$-value $<0.01, * * * p$-value $<0.001$

do the Americans on these same triads. This is true with respect to both the animate (dog-bear) and the inanimate pairs (flower-grass). For example, $18 \%$ of the time, within the same triad, Russians pair bear with flower (same gender) whereas Americans do the same only $2 \%$ of the time which is significantly less $(p$ -value $<0.01$ ); and (3) Russians make significantly more similarity pairings by "other" criteria than do Americans. This also true for the animate pair (dogbear) but not for the inanimate pair (flower-grass).

Considered together, the results appear to provide modest but consistent support for the proposition that, with respect to Russian, linguistic noun gender distinctions play a role in cognitive ethnobiological categorization. In general, about $20 \%$ of cognitive choices appear to reflect a gender influence. Curiously, this is rather close to Kirk and Burton's (1976) finding that approximately $27 \%$ of their results using triad sorts of "flying animals" were based on Kikuyu noun classifications. More extensive research employing other cognitive measures and larger samples of a variety of words and respondents needs to be undertaken in the future. Other gendered languages could also be investigated along similar lines. It is important to recognize that at this point, our project deals only with perceived similarities and differences in objects antecedent to actual behavioral categorization and classification. Considering these auspicious results, a more thorough field investigation using increasingly precise, recognized classification techniques and measures (e.g., pile-sorts, cf. Weller 1998) should be conducted.

After a thorough review, Rhoades et al. (2010:25) conclude: "a robust finding in folk biological research is that across the world's cultures, individuals categorize and name animals (as well as plants) in fundamentally similar ways." Our research is clearly commensurate with this insofar as both groups are similar in assigning the bulk of the similarities among species to phenotype (overall, $87 \%$ in the case of 
American English and 64\% in the case of Russian). Nonetheless, this statistic also reveals a significant difference between the two languages, leaving a lot to be explained. On the basis of our results, we believe a substantial amount of this difference (roughly 20\%) can be attributed to the difference in structure between the two languages. In the future, greater attention needs to be invested in discovering the nature of the residual category of "other" choices. Indeed, more data need to be collected and analyzed regarding folk biological categories to determine the reasons and subjective bases for various categorization processes. This could presumably be initiated simply by asking respondents to explain why they made the choices they did in any classification task.

Many questions also arise concerning how linguistic features (e.g., gender and animacy) may influence cognitive processes (e.g., categorization and discrimination). Perhaps it is as Dilkina et al. (2007:219) assert, that "linguistic information helps shape semantic representations throughout development." If so, multilinguals, for instance, who did not speak Russian originally, might be expected to cognize members of folk biological categories in different ways. It is worthy to note that research along these lines has recently been undertaken (e.g., Hrzica et al. 2015).

Looking ahead, more investigations along similar lines with other gendered languages are indicated. We think these findings are also congruent with the linguistic relativity hypothesis (Lucy 1997), insofar as they offer evidence of the influence of language on thought along the lines suggested by Sapir (Mandelbaum 1949) and Whorf (Carol 1956). The practical benefits of these inquiries include understanding more about the role language plays in biological information processing and, importantly, how to facilitate better cross-cultural and crosslinguistic acquisition, communication, and understanding.

\section{Notes}

${ }^{1}$ American English does extend gendered pronouns "she" and "he" to nouns in tropes such as: "she's a sturdy sailing ship"; "she's a dependable gun"; "Mother Nature"; "Father Time"; "she’s our Nation", etc.

${ }^{2 " D o g " ~ a n d ~ " b e a r " ~ e x i s t ~ a t ~ t h e ~ f o l k ~ g e n e r i c ~ r a n k, ~ a n d ~}$ "flower" and "grass" at the intermediate level; while these terms may differ subtly in rank, they were chosen as they are easily perceived and readily recognized by respondents.

\section{Acknowledgements}

We wish to thank Margaret Robbins for her help collecting data at the University of Missouri and Aleksandr Pakhomov for assisting in collecting and processing the Russian data.

\section{Declarations}

Permissions: None declared.

Sources of funding: None declared.

Conflicts of Interest: None declared.

\section{References Cited}

Baker, M. 2003. Lexical Categories: Verbs, Nouns, and Adjectives. Cambridge University Press, Cambridge, $\mathrm{UK}$.

Beresford, M. 1965. Complete Russian Course for Scientists. Clarendon Press, Oxford, UK.

Berlin, B. 1992. Ethnobiological Classification: Principles of Categorization of Plants and Animals in Traditional Societies. Princeton University Press, Princeton, NJ.

Brown, C. 2001. Linguistic Ethnobiology: Amerindian Oak Nomenclature. In Ethnobiology at the Millennium: Past Promise and Future Prospects, edited by R. Ford, pp. 111-148. Anthropological Papers 91, University of Michigan, Museum of Anthropology, Ann Arbor, MI.

Burton, M., and L. Kirk. 1976. The Semantic Reality of Bantu Noun Classes: The Kikuyu Case. Studies in African Linguistics 7:157-74.

Carroll J., ed. 1956. Language, Thought, and Reality: Selected Writings of Benjamin Lee Whorf. MIT Press, Cambridge, MA.

Dilkina, K., J. McClelland, and L. Boroditsky. 2007. How Language Affects Thought in a Connectionist Model. Proceedings of the Annual Meeting of the Cognitive Science Society_29:215-220.

Hrzica, G., M. Palmovic, M. Kovacevic, M. Voelkova, K. Ivanova, and E. Galkina. 2015. Animacy and Case in the Acquisition of Differential Object Marking in Croatian and Russian. Revue de Linguistique Romane 60:351-368.

Hunn, E., and C. Brown. 2011. Linguistic Ethnobiology. In Ethnobiology, edited by E. Anderson, D. Pearsall, E. Hunn, and N. Turner, pp. 319-334. Wiley-Blackwell, Hoboken, NJ. 
Kilarski, M. 2013. Nominal Classification: A History of its Study from the Classical Period to the Present. John Benjamin, Philadelphia, PA.

Klenin, E. 1983. Animacy in Russian: A New Interpretation. Slavica Publishers, Columbus, $\mathrm{OH}$.

Kravchenko, A. 2002. The Cognitive Roots of Gender in Russian. Glossos 3:1-13.

Lucy, J. 1997. Linguistic Relativity. Annual Review of Anthropology 26:291-312. DOI:10.1146/ annurev.anthro.26.1.291.

Mandelbaum, D., ed. 1949. The Selected Writings of Edward Sapir in Language, Culture, and Personality. University of California Press, Berkeley, CA.

Nolan, J. M., and M. C. Robbins. 2001. Emotional Meaning and the Cognitive Organization of Ethnozoological Domains. Journal of Linguistic Anthropology 11:240-249. DOI:10.1525/

jlin.2001.11.2.240.
Weller, S. 1998. Structured Interviewing and Questionnaire Construction. In Handbook of Methods in Cultural Anthropology, edited by H. R. Bernard, pp. 365-410. Altamira Press, Walnut Creek, CA.

Winkler-Rhoades, N., D. Medin, S. Waxman, J. Woodring, and N. Ross. 2010. Naming the Animals that Come to Mind: Effects of Culture and Experience on Category Fluency. Journal of Cognition and Culture 10:205-220. DOI:10.1163/156853710x497248.

Zubin, D., and K. Kopke. 1986. Gender and Folk Taxonomy: The Indexical Relation between Grammatical and Lexical Categorization. In Noun Classes and Categorization, edited by C. Craig, pp. 139180. John Benjamin, Philadelphia, PA. 